\title{
La actividad económica de los municipios alemanes en el mercado de la producción de energía*
}

\author{
Martin BURGI \\ Catedrático de Derecho Público, Derecho Administrativo Económico, Medioambiental y Social \\ Ludwig-Maximilians-Universität München
}

\begin{abstract}
RESUMEN
Este artículo se ocupa del marco jurídico de la producción energética por empresas municipales en Alemania. En él se analizan en primer lugar las circunstancias actuales de la iniciativa económica de las entidades locales y la evolución en el sector energético. Seguidamente se estudian las ventajas, pero también los peligros, de la actuación económica municipal en el ámbito de la producción de energía. Por último, el autor aporta una visión de conjunto sobre el marco jurídico alemán en vigor y de en qué medida este marco permite $o$, incluso, fomenta la participación municipal en el mercado energético.
\end{abstract}

Palabras clave: iniciativa económica municipal; producción energética; energías renovables; actividad municipal supralocal.

\section{ABSTRACT}

The article deals with the legal framework of energy production by municipal enterprises in Germany. The author first analyses the current conditions with regard to economic activities by municipalities in general and developments in the energy sector in particular. Subsequently, the advantages, but also the dangers of economic activity by municipalities in the field of energy production are pointed out. The author then gives an overview of the

* Artículo finalizado en febrero de 2021. La traducción del original alemán ha corrido a cargo de J. CASTILLO ABELla (Universidad Autónoma de Madrid). En la traducción se han adaptado las citas de normas alemanas al formato habitual en España. No obstante, se han mantenido las citas jurisprudenciales originales para mayor facilidad de localización.

Abreviaturas utilizadas: GO NRW: Gemeindeordnung für das Land Nordrhein-Westfalen (código municipal del estado federado de Renania del Norte-Westfalia); GG: Grundgesetz (Ley Fundamental de Bonn); STJCE: Sentencia del Tribunal de Justicia de las Comunidades Europeas; TFUE: Tratado de Funcionamiento de la Unión Europea. 
extent to which the current legal framework in Germany allows municipal involvement in the energy market or even promotes it.

Keywords: municipal economic activity; energy generation; renewable energies; supra-local municipal activity.

SUMARIO: I. SITUACIÓN ACTUAL: 1. La iniciativa económica de las entidades locales. 2. Evolución en el ámbito del mercado energético.-II. VENTAJAS Y PELIGROS: 1. Ventajas de la participación local en la producción energética. 2. Peligros de la participación local en la producción energética.-III. MARCO JURÍDICO: 1. Derecho de la Unión Europea. 2. Marco constitucional. 3. Legislación de régimen local. 3.1. Previsiones generales. 3.2. Actividad suprarregional.-IV. CONCLUSIONES.-V. BIBLIOGRAFÍA.

\section{SITUACIÓN ACTUAL}

\section{La iniciativa económica de las entidades locales}

El grado de urbanización en Alemania varía mucho de un Land a otro. Mientras que en Baviera hay muchos distritos (Kreise) con municipios pequeños y solo unas pocas ciudades, en Renania del Norte-Westfalia (un Land en el que predominan las ciudades) hay menos municipios que son más grandes y pueden considerarse ciudades de tamaño medio y grande ${ }^{1}$. Con todo, resulta destacable la importancia que tienen en la vida económica alemana los municipios a partir de 5.000 habitantes. La Federación de Empresas Locales alemana ${ }^{2}$ sostiene que sus miembros, aproximadamente 1.500 , tienen un volumen agregado de negocios por importe de 119.000 millones de euros ${ }^{3}$. Existe una larga tradición de actividad económica local, es decir, de participación de las entidades locales en el intercambio de prestaciones y, en su caso, contraprestaciones económicas en el mercado ${ }^{4}$.

De esta forma, la actividad económica local tiene que ver con el modo de la actuación de la entidad local. Para cumplir con los fines previamente establecidos (como puede ser la provisión de energía eléctrica a los ciudadanos) las entidades locales participan en el intercambio de prestaciones y contraprestaciones financieras, en lugar de

1 Esto puede verse en el gráfico disponible en https://www.bbsr.bund.de/BBSR/DE/forschung/raumbeobachtung/Raumabgrenzungen/deutschland/kreise/siedlungsstrukturelle-kreistypen/kreistypen.html (consultado el 15 de enero de 2021).

2 Verband der kommunalen Unternehmen, que representa los intereses económicos de empresas locales que desempeñan servicios locales o proveen de bienes.

3 Esta información, referida al ejercicio 2018, puede consultarse en la propia web de la Federación: https:// www.vku.de/verband/ueber-uns/ (consultado el 15 de enero de 2021).

4 Sobre el concepto de iniciativa económica local (kommunale Wirtschaftsbetätigung) vid. M. BuRGI, Kommunalrecht, 6. ${ }^{a}$ ed., C. H. Beck, Múnich, 2019, \$17, ap. 3. 
actuar ejerciendo alguna potestad como podría ser a través de mandatos, prohibiciones o medidas regulatorias. Por ello, las entidades locales no actúan aquí a través de órganos administrativos (Administración local inmediata), sino que crean a tal fin lo que se ha denominado empresas públicas. Estas pueden ser de naturaleza jurídica tanto pública como privada. La forma jurídica más común es la de la sociedad de responsabilidad limitada, pues su ley reguladora contiene normas dispositivas lo suficientemente flexibles como para otorgar a la entidad local influencia decisoria sobre la sociedad. Por el contrario, el régimen jurídico de las sociedades anónimas deja mucho menos margen para una configuración ventajosa. También hay que mencionar la creciente cifra y variedad de las formas de cooperación para la realización de actividades locales, que pueden estar compuestas por empresas públicas o por actores tanto del sector público como del privado.

Este artículo se centra en la actividad económica de los municipios y no de los distritos.

\section{Evolución en el ámbito del mercado energético}

Prácticamente en ningún ámbito de nuestro día a día dejamos de estar rodeados de energía, ya sea la calefacción en nuestras viviendas, la operación de automóviles o trenes o la energía eléctrica que utilizan nuestros dispositivos tecnológicos. Ello justifica la importancia de un mercado energético funcional que pueda cubrir la creciente necesidad de energía de la población. Esto incluye todos los servicios relacionados con la energía a la hora de suministrar electricidad, gas, calefacción y refrigeración. Puede distinguirse aquí entre los niveles de generación o producción primaria de energía, la distribución y el transporte (operación de la red) y la comercialización, así como numerosos servicios adicionales 5 .

El desarrollo del mercado energético ha tenido una dinámica particular en los últimos años. Su impulso se ha debido a factores técnicos, ecológicos y políticos. Así, el gobierno federal alemán ha establecido el objetivo de impulsar la denominada transición energética, que tiene como fin abastecer a la sociedad y a la economía alemanas, de forma permanente, con energía de fuentes sostenibles, renovables o regenerativas (en conjunto, energías renovables). Al mismo tiempo, se trata así de reducir el porcentaje que representa la producción energética basada en petróleo y carbón en el mercado alemán ${ }^{6}$. Uno de los muchos motivos para ello es que las energías fósiles se obtienen de fuentes finitas, pero la demanda energética mundial no hace más que aumentar. Por otra parte, hay que importar las energías fósiles, algo que hace a Alemania dependiente de regiones geopolíticamente inseguras, mientras que las energías renovables se obtienen

5 Vid. M. BURGI, Neuer Ordnungsrahmen für die energiewirtschaftliche Betätigung der Kommunen, op. cit., p. 23.

6 Vid. https://www.bpb.de/nachschlagen/lexika/lexikon-der-wirtschaft/159947lenergiewende (consultado el 15 de enero de 2021). 
in situ ${ }^{7}$. Pero, sobre todo, la combustión de fuentes fósiles emite a la atmósfera gases de efecto invernadero, como el dióxido de carbono, que aceleran el cambio climático y sus devastadoras consecuencias para la población mundial y el medio ambiente ${ }^{8}$. En Alemania, la transición energética también implica mayor rapidez en el abandono de la energía nuclear, pues ello conlleva también mayor presión a la hora de desarrollar nuevas tecnologías y productos para el establecimiento de energías renovables y para el aumento de la eficiencia energética. En la actualidad, ya el 42 por 100 del consumo eléctrico en Alemania se cubre con energía de fuentes renovables. Para alcanzar los objetivos climáticos de la Unión Europea, las energías renovables deberán representar en 2050 un mínimo del 80 por 100 del consumo eléctrico bruto?

La base fundamental de todo ello es la innovación técnica. Así, por ejemplo, la apuesta por instalaciones de energía eólica más modernas que garanticen que incluso las energías renovables dependientes de la meteorología también pueden ser eficientes y merecen ser integradas en el sistema eléctrico. Además, la competencia en el mercado produce continuamente productos y servicios nuevos e innovadores que pueden favorecer este desarrollo. En este sentido, la compañía Stadtwerke München GmbH (empresa pública cuya titularidad corresponde en su totalidad a la ciudad de Múnich) opera en la región de Múnich más de 30 instalaciones fotovoltaicas, 14 instalaciones hidráulicas, 2 instalaciones de biogás, 5 instalaciones geotérmicas y 2 instalaciones eólicas ${ }^{10}$. Otro factor que tiene que ver con la transición energética es el cambio de conciencia ecológica de la ciudadanía, pues estos cambios son a su vez asumidos por los políticos y quedan ligados a ciertos objetivos. Así sucedió con el abandono de la energía solar por parte de Alemania, que fue una reacción a la catástrofe nuclear en Fukushima y a la creciente importancia de la protección del clima y el medio ambiente en el debate público mundial. Todo ello exige de la política la renuncia a energías fósiles ${ }^{11}$. Y no hay que olvidar que la actividad en el sector energético puede suponer una atractiva fuente de ingresos para las entidades locales. Estos nuevos ingresos pueden ser un instrumento de apoyo (en forma de «subvenciones cruzadas») a las entidades locales de cara a la prestación de los servicios locales deficitarios como el transporte público de personas. No obstante, aunque la desoladora situación financiera de algunos municipios pueda suponer un gran incentivo para estas tareas, sería erróneo reducir la motivación de todos ellos a esta circunstancia ${ }^{12}$.

7 Cfr. https://www.bundesregierung.de/breg-delthemen/energiewendelfragen-und-antworten/erneuerbare-energien/allgemeines-451866 (consultado el 15 de enero de 2021).

8 Vid. https://www.bmu.delthemen/klima-energie/ (consultado el 15 de enero de 2021).

9 Cfr. https://www.bmwi.de/Redaktion/DE/Dossier/strommarkt-der-zukunft.html (consultado el 15 de enero de 2021).

10 Vid. también https://www.swm.delenergiewende (consultado el 15 de enero de 2021).

11 Para abordar los retos que esto plantea en Alemania, vid. J.-Ch. PIELOW y T. SCHUELKEN, «Evolución de un mercado energético eficiente en Alemania», en M. Darnaculleta Gardella, J. Esteve Pardo y M. Ibler (coords.), Nuevos retos del Estado garante en el sector energético, Marcial Pons, Madrid, 2020, pp. 83 y ss.

12 Vid. también M. BuRGI, "Daseinsvorsorge und Energieversorgung - Teilnahme der Kommunen am energiewirtschaftlichen Wettbewerb», en M. KMENT (coord.), Energiewirtschaft und kommunale Selbstverwaltung, Mohr Siebeck, Tübingen, 2018, pp. 1 y ss., esp. p. 6. 
Hasta hace diez años, las empresas públicas locales activas en la distribución y el transporte de energía operaban en su gran mayoría redes de baja y media tensión. Es decir, su actividad consistía en conectar los puntos de consumo final con la red eléctrica o de gas (local o regional) y en mantener, operar y garantizar la estabilidad de estas redes. Esto ha llevado a una descentralización e internacionalización crecientes del mercado de producción energética, de forma que cada vez actúan en él como productoras más empresas locales de pequeño y medio tamaño. Anteriormente, sin embargo, las empresas locales eran anecdóticas entre los productores energéticos convencionales. El ejemplo más conocido era el de la Rheinisch-Westfälische Elektrizitätswerk (RWE), la empresa municipal de la ciudad de Essen fundada en 1898 y que desde hace tiempo está en manos mayoritariamente privadas y se ha convertido en líder internacional en el mercado energético ${ }^{13}$. Con todo, el desarrollo del mercado también ha llevado a que, en los últimos años, las empresas locales se involucren cada vez más en el mercado energético: por un lado, en la producción eléctrica a través de centrales termoeléctricas o de gasificación o en instalaciones con fuentes renovables; y, por otro, en la producción térmica mediante plantas de cogeneración. Según las cifras de la Federación de Empresas Locales, se está produciendo un aumento de la cuota del mercado energético que corresponde a la producción local de energía ${ }^{14}$.

En numerosas ocasiones las entidades locales no actúan solas, sino que se unen con otros actores para afrontar la tarea de proveer de energía aprovechando las sinergias que surjan de la unión. Así, la Stadtwerke München participa en casi un 50 por 100 en el capital de la sociedad Marquesado Solar, S. L., que es la que opera la instalación termosolar Andasol 3 en la provincia de Granada ${ }^{15}$. Más allá de la colaboración con actores privados, en este ámbito es cada vez más frecuente la cooperación entre entidades locales, con distinta forma e intensidad, ya sea dentro de un mismo Land o con entidades pertenecientes a otro. Dentro de la gran variedad de formas que adopta esta cooperación pueden encontrarse colaboraciones ligadas a un proyecto, conglomerados societarios de varias empresas locales o la participación conjunta en sociedades ${ }^{16}$. A título ilustrativo, el próximo verano la empresa Regionalwerk Chiemgau Rupertwinkel comenzará su actividad como productora de energía, para lo cual se han unido 15 entidades locales del sureste de Alta Baviera ${ }^{17}$. En esa misma región, la ciudad de Fürstenfeldbruck (con alrededor de 40.000 habitantes) apuesta por la expansión de fuentes renovables. Así,

13 Cfr. https://www.rwe.com/der-konzern/geschichte (consultado el 15 de enero de 2021).

14 Vid. VKU-Erzengungsumfrage 2016, disponible en https://www.vku.delvku-positionen/kommunale-energieversorgung/vku-erzengungsumfrage-2016/?sword_list[]=erzeugungsumfrageלtno_cache=1 (consultado el 15 de enero de 2021).

15 Vid. la página 256 del anexo del «Finanzdaten- und Beteiligungsbericht» de la ciudad de Múnich, que puede descargarse en https://www.muenchen.de/rathaus/Stadtverwaltung/Stadtkaemmerei/Presse-Publikationen/Finanzpublikationen/FDB.html (consultado el 18 de enero de 2021).

16 Vid. R. SiEvEn, Kommunale Energieerzeugung in der Energiewende, Universitätsverlag Göttingen, Göttingen, 2019, p. 104.

17 Cfr. https://publicus.boorberg.de/15-kommunen-in-oberbayern-gruenden-energieversorger/ (consultado el 22 de enero de 2021). 
desde noviembre de 2014, una instalación eólica cerca de Mammendorf es gestionada por la sociedad WindEnergieAnlage Mammendorf GmbH \& Co. KG, en cuyo capital participan la empresa municipal Stadtwerke Fürstenfeldbruck en un 40 por 100 y los municipios de Fürstenfeldbruck y Mammendorf (este último con 5.000 habitantes) en un 30 por 100 cada uno ${ }^{18}$.

Más allá de estos ejemplos de cooperación regional hay también casos de cooperación transfronteriza. Tras la sociedad Global Tech I Offshore Wind GmbH, que opera en Hamburgo un parque eólico de 400 megavatios, se encuentran proveedores regionales de energía cuya cuota en su capital es casi de un 75 por $100^{19}$. Además de la Stadtwerke München, entre ellos se encuentran Entega AG, uno de los proveedores regionales más grandes de Alemania y cuyo 93,28 por 100 está en manos de la ciudad de Darmstadt (unos 160.000 habitantes) a través de HEAG Holding $\mathrm{AG}^{20}$, y Axpo, el mayor productor suizo de energías renovables, que es propiedad al cien por cien de los cantones y empresas de servicios públicos cantonales del noreste de Suiza ${ }^{21}$.

\section{VENTAJAS Y PELIGROS}

\section{Ventajas de la participación local en la producción energética}

Como ya se ha señalado, las empresas locales tienen una función instrumental. El modo en el que estas intervienen económicamente se elige en función de consideraciones relativas a las tareas, los aspectos financieros y al orden político en general. Y ello, a su vez, sirve para alcanzar mejor los objetivos tras esa intervención, como pueden ser la garantía del suministro energético, la razonabilidad de los precios o el respeto al medio ambiente $^{22}$. Con ello también se facilita la participación ciudadana en la ejecución de estas tareas a través de la entidad local. Si bien las entidades locales deben asegurarse de que se les reconocen facultades de control de las sociedades en cuyo capital participan (mayoritariamente), sería mucho más difícil imponer fines políticos a terceras personas que, por tanto, cuentan con protección iusfundamental. Puede citarse aquí la consulta ciudadana de 2017 llamada "Raus aus der Steinkohle» («no más carbón»), relativa al cierre anticipado del bloque 2 de la central térmica del norte de Múnich. Una vez conocido el resultado, que reflejaba una mayoría de votos a favor del cierre a finales de 2022, fue suficiente para materializar esa decisión una declaración formal del alcalde de Múnich

$18 \mathrm{Vid}$. https://www.stadtwerke-ffb.deldelunternehmen/erzengung/windenergie (consultado el 19 de enero de 2021).

19 Vid. https://globaltechone.de/ueber-uns/ (consultado el 18 de enero de 2021).

${ }^{20}$ Cfr. https://www.entega.ag/ueber-entega/konzern/\#c2500 (consultado el 18 de enero de 2021).

21 Cfr. https://www.axpo.com/ch/delueber-uns/portraet.html (consultado el 18 de enero de 2021).

22 Cfr. M. BuRGI, Neuer Ordnungsrahmen für die energiewirtschaftliche Betätigung der Kommunen, op. cit., p. 25 y ss.; $y$ «Daseinsvorsorge und Energieversorgung - Teilnahme der Kommunen am energiewirtschaftlichen Wettbewerb", op. cit., p. 6. 
en ese sentido. Si se hubiera tratado de una central térmica privada, ni siquiera habría cabido la posibilidad de celebrar la consulta ${ }^{23}$. Una mayor aceptación de estas decisiones por parte de la ciudadanía está ligada al mayor margen de participación en la toma de decisiones que presenta la actividad local de producción energética frente a los productores privados.

\section{Peligros de la participación local en la producción energética}

Sin embargo, el creciente papel que desempeñan las entidades locales en la producción de energía también tiene una vertiente negativa: una actividad tan complicada y exigente como la provisión de energía puede superar la capacidad de una entidad local. En primer lugar, tiene que respetar el complejo marco legal regulatorio, que va desde los numerosos requisitos edificatorios y medioambientales de la construcción de una central energética hasta las normas contenidas en la Ley del Sector Energético (Energiewirtschaftsgesetz), que a su vez derivan de la transposición de las Directivas europeas correspondientes. Pero es que, además de ello, el municipio tiene que tener en cuenta muchos otros aspectos de la política local para conseguir poner en marcha un buen y completo sistema de gestión energética. Se podría llegar aun a una retirada de operadores privados (quizá incluso provocada por la existencia de ventajas ilegítimas) que llevara aparejada una disminución de los ingresos tributarios locales. También hay que pensar que la actuación a través de sociedades de Derecho privado conlleva una cierta independencia del medio propio, aun cuando existan facultades directivas de la entidad local. Esto implica una pérdida de control respecto de la actuación local a través de los órganos de la propia entidad local, a pesar de que esta se reserve aquellas facultades de control sobre la empresa local que sean acordes con el Derecho de sociedades. Con todo, la actuación a través de empresas locales siempre significa un mayor margen de influencia que el que tienen las entidades locales sobre los actores "puramente» privados que realicen esa actividad. El Derecho económico local tiene presentes estas consideraciones al establecer los límites a la actividad local en el mercado (vid. infra el apartado III.3.3.1).

\section{MARCO JURÍDICO}

La iniciativa económica de las entidades locales plantea numerosos interrogantes que (parcialmente) son objeto de controversia en Alemania. Debido a la creciente interrelación de la actividad económica en la Unión Europea, en esta materia no solo hay que tener en cuenta el Derecho constitucional y local, sino también el europeo.

23 Vid. https://www.muenchen.de/rathaus/Stadtpolitik/Wahlergebnisse/Buerger_Volksentscheide/B-rgerentscheid--Raus-aus-der-Steinkohle--.html (consultado el 19 de enero de 2021). 


\section{Derecho de la Unión Europea}

El Derecho europeo es neutral respecto de la iniciativa económica estatal o local y se caracteriza por la libertad de organización ${ }^{24}$. El art. 345 TFUE permite a los Estados miembros la atribución de la propiedad de empresas a organismos públicos o privados. Más allá de esto, no pueden extraerse del Derecho primario requisitos relativos a la licitud de la iniciativa económica local (es decir, no ofrece más respuesta alguna a si puede haberla o no). Por su parte, los apartados 1 y 2 del art. 106 TFUE solamente establecen que tanto a las empresas públicas como a las privadas deben aplicárseles las mismas normas de Derecho tributario y de la competencia.

Por lo demás, el Derecho europeo condiciona en gran parte el cómo, es decir, contiene normas sobre la actuación económica local. La Comisión Europea ve los «servicios de interés general» como parte irrenunciable del modelo social europeo y como uno de los valores comunes de todas las sociedades europeas ${ }^{25}$. En esta materia subyace al Derecho europeo la idea de que los servicios vitales esenciales (Daseinsvorsorge) se prestan mejor cuando resultan de la competencia entre distintos proveedores. De este modo, el Derecho europeo trata ante todo de crear las condiciones para que esos proveedores de servicios puedan competir en igualdad. Un objetivo adicional es la correcta prestación del servicio, independientemente de si lo presta una empresa local o una privada ${ }^{26}$.

También hay que tomar en consideración aquí el art. 14 TFUE, según el cual la Unión y los Estados miembros deben velar en el marco de sus competencias por que los principios y condiciones aplicables al funcionamiento de los «servicios de interés económico general» permitan cumplir su cometido a quienes los prestan. Entre estos servicios de interés económico general (en el sentido de los arts. 14 y 106.2 TFUE) se encuentra también la provisión de energía en el marco de la provisión pública de energía eléctrica ${ }^{27}$.

El Derecho primario establece otras normas relativas sobre la iniciativa económica de las entidades locales en los arts. 101 y 102 TFUE, que regulan la conducta competencial y las libertades fundamentales, respectivamente. Además, en esta materia pueden ser problemáticas las normas sobre ayudas de Estado en los arts. 107 y 108 TFUE. El art. 107.1 TFUE prohíbe, en principio, las ayudas de Estado, salvo que se trate de alguno de los supuestos exceptuados en los apartados 2 y 3 de ese artículo o que la Comisión

\footnotetext{
${ }^{24}$ Cfr. Comunicación de la Comisión Europea del 20 de septiembre de 2000 «Los servicios de interés general en Europa» [COM (2000), 580 final).

25 Vid. Comisión de las Comunidades Europeas, Libro Verde sobre los servicios de interés general, de 21 de mayo de 2003, COM (2003) 270 final, ap. 2. p. 36.

${ }_{26}$ Cfr. M. Burgi, Neuer Ordnungsrahmen für die energiewirtschaftliche Betätigung der Kommunen, op. cit.,

${ }_{27}$ Con más referencias Ch. Jung, «Art. 106 AEUV», en Ch. Callies y M. Ruffert (coords.), EUV/ AEUV Kommentar, 5.a ed., C. H. Beck, Múnich, 2016, ap. 36.
} 
Europea haya declarado que esa ayuda es compatible con el mercado interior (tras el llamado procedimiento de notificación). Por ello, medidas de apoyo a las empresas públicas locales podrían ser consideradas ayudas de Estado según el market-investor-Test si se concluye que el titular de una empresa privada en una situación comparable a la pública no habría actuado de esa forma siguiendo criterios de rentabilidad prospectiva ${ }^{28}$. Si efectivamente se trata de un trato preferente, según la doctrina de la STJCE Altmark-Trans, solo se evita caer en la ayuda de Estado si se cumplen ciertos requisitos, aun cuando la contraprestación del trato preferente sea la prestación de un servicio económico local ${ }^{29}$.

En caso de que la actividad económica de una entidad local vulnerase estas disposiciones podría aplicarse el art. 106.2 TFUE, que permite exceptuar en este ámbito a las entidades locales «en la medida en que la aplicación de dichas normas no impida, de hecho o de derecho, el cumplimiento de la misión específica a ellas confiada ${ }^{30}$. En principio, por tanto, el Derecho europeo no se opone a la iniciativa económica local en la producción energética.

\section{Marco constitucional}

La Constitución alemana (Ley Fundamental de Bonn, GG) no contiene ni una prohibición ni requisitos explícitos sobre la actividad empresarial del Estado y de las entidades locales. No obstante, en tanto que actuación estatal debe responder también a la realización del interés general (fin público), aunque sea a través de una empresa. Esto se aplica también a las entidades locales, que también se enmarcan en la esfera estatal. De esta forma, la actividad local de producción de energía no se basaría en una autonomía privada con protección iusfundamental, sino que debe venir legitimada por la realización del interés general, como cualquier otra actuación estatal ${ }^{31}$. La garantía de provisión de energía ya ha sido reconocida por el Tribunal Constitucional Federal alemán como una actividad de vital importancia pública. Por ello, no puede caber ya duda alguna de que la producción energética a través de empresas públicas municipales para proveer al municipio de electricidad, gas, calefacción o refrigeración responde a un fin público ${ }^{32}$.

La garantía de autonomía local del art. 28.2 GG tiene una relevancia central en el marco jurídico-constitucional de la actividad económica de las entidades locales. Las constituciones de los distintos Länder contienen disposiciones similares que difieren de aquella en pequeños aspectos y, por ello, no serán objeto de estudio en este trabajo. El

28 Cfr. M. Burgi, Kommunalrecht, op. cit., $\$ 17$, ap. 29.

29 Para los criterios vid. la sentencia del Tribunal de Justicia de las Comunidades Europeas de 24 de julio de 2003 en el asunto C-280/00 (ECLI:EU:C:2003:415), en Neue Juristische Wochenschrift, 2003, pp. 2515 y ss.

30 Vid. M. BurgI, Kommunalrecht, op. cit., $\$ 17$, ap. 31.

31 Vid. M. BurgI, Neuer Ordnungsrahmen für die energiewirtschaftliche Betätigung der Kommunen, op. cit., p. 56.

32 Cfr. BVerfG, Neue Juristische Wochenschrift, 1984, pp. 1872 y ss., esp. p. 1873. 
art. 28.2 GG reconoce a los municipios el derecho de regular todos los asuntos de la comunidad en nombre propio y en el marco de la ley. Entre otros aspectos, se protege con ello la autonomía del municipio al asumir tareas frente a la intervención estatal. Esto incluye tanto la capacidad de asumir tareas en forma de actividad económica como la capacidad de decidir qué forma organizativa se elige para el cumplimiento de cada tarea, también cuando esa forma organizativa sea la societaria. La garantía de autonomía local protege asimismo la soberanía de cooperación, es decir, la decisión del municipio de cooperar con otras entidades locales ${ }^{33}$. En consecuencia, se limita cualquier medida de la Federación o del Land que restrinja la iniciativa económica local, para lo cual deberá estar debidamente motivada.

El fundamento y también el límite de la competencia municipal son los asuntos de la comunidad local. Por estos entiende el Tribunal Constitucional Federal alemán «las necesidades e intereses radicadas en la comunidad o que tienen una especial relación con esta, y que por tanto son comunes a los habitantes del municipio porque afectan a la vida comunitaria en él» ${ }^{34}$. Esto quiere decir que el ámbito de aplicación del art. 28.2 GG no se limita solo a la actividad municipal comprendida dentro del término municipal. También la actividad «extraterritorial» del municipio puede estar protegida por el art. 28.2 GG cuando tenga relación con sus habitantes. Ese sería el caso de un municipio que opera una instalación eléctrica fuera de su término, siempre que solo proveyera de energía eléctrica a sus habitantes. Eso sí, el municipio es libre de ampliar el ámbito territorial de la garantía constitucional de autonomía local mediante la cooperación con otras entidades locales ${ }^{35}$. No obstante, si la producción se encuentra fuera del municipio y ya no existe relación con los habitantes, se tratará de una actividad económica supralocal y, por tanto, no estará protegida por la garantía de autonomía local. Por ello, el municipio no puede invocar esta garantía frente a limitaciones por parte del Estado de su actividad de producción energética supralocal.

Sin embargo, esto no excluye que el municipio pueda actuar en ese sector. Lo que puede suceder entonces es que el legislador del Land incluya en la normativa de régimen local una cláusula que permita en casos excepcionales la actividad supralocal de los municipios, como de hecho ya ha sucedido en varios Länder (vid. infra el apartado III.3) ${ }^{36}$. En estos casos hay que considerar el juego de estas cláusulas con la GG, especialmente

33 Cfr. M. BuRgI, Kommunalrecht, op. cit., $\$ 6$, ap. 33.

34 El texto original es el siguiente: diejenigen Bedürfnisse und Interessen, die in der örtlichen Gemeinschaft wurzeln oder auf sie einen spezifischen Bezug haben, die also den Gemeindeeinwohnern gerade als solchen gemeinsam sind, indem sie das Zusammenleben und -wohnen der Menschen in der (politischen) Gemeinde betreffen. Vid. BVerfG, Neue Zeitschrift für Verwaltungsrecht, 1989, pp. 347 y ss., esp. p. 350.

35 Vid. M. BuRGI, Neuer Ordnungsrahmen für die energiewirtschaftliche Betätigung der Kommunen, op. cit., p. 81 .

${ }_{36}$ Cfr. M. Burgi, Kommunalrecht, op. cit., $\$ 17$ ap. 49; sobre la necesidad y el alcance de dicha cláusula en el ámbito del suministro de energía en el código municipal del Estado federado de Renania del Norte-Westfalia vid. M. BURGI, Neuer Ordnungsrahmen für die energiewirtschaftliche Betätigung der Kommunen, op. cit., pp. 81 y ss. 
con su art. 28.2. Así, por un lado, la garantía institucional de la autonomía local podría verse menoscabada por su excesiva extensión más allá de los asuntos locales. Por otro, podría ser invocada como derecho subjetivo de defensa por los municipios en cuyo término se desarrolle la actividad supralocal del municipio «activo». Con todo, tampoco hay que olvidar que el efecto adverso de una actividad municipal supralocal es indirecto, pues se trata de un simple actor económico más en el mercado que no afecta negativamente a la autonomía de otro municipio ni a las tareas que este haya asumido ${ }^{37}$. Siempre que se cumplan estas previsiones, la actividad municipal en el sector energético puede extenderse más allá del Land al que pertenezcan e incluso del territorio de la República Federal de Alemania. En definitiva, la GG deja en manos de la autonomía local la decisión de ejercer la iniciativa económica, si bien el legislador de cada Land puede influir en ella notablemente a través del desarrollo y concreción de la GG en la legislación de régimen local correspondiente ${ }^{38}$.

\section{Legislación de régimen local}

Junto a lo ya expuesto, existen otras normas, especialmente a nivel federal, que deben ser tenidas en cuenta tanto por los actores económicos privados como por las entidades locales (así, el Derecho de los sectores regulados, del medio ambiente o de la competencia). En Alemania, la competencia legislativa sobre régimen local corresponde a los Länder según los arts. 30 y 70 GG. Todos los códigos municipales de los Länder contienen normas que limitan si una entidad local puede ejercer actividades económicas. También prevén otros requisitos, especialmente en relación con la elección de formas jurídico-privadas. Así, por ejemplo, se establece la preferencia de ciertas formas organizativas o la necesidad de reflejar en el contrato de sociedad o los estatutos el fin público que se trata de cumplir. Específicamente en el sector energético, algunos Länder cuentan desde 2010 con normas que permiten que las empresas municipales actúen más allá de las fronteras del Land $^{39}$. En lo que sigue se hará referencia a estas normas con el ejemplo del art. 107.a) del código municipal de Renania del Norte-Westfalia (GO NRW), que fue introducido mediante la Ley para la revitalización del Derecho económico municipal de 2010. Este artículo asocia determinadas consecuencias jurídicas a la existencia de una actividad municipal en el sector energético. Este nuevo artículo responde a una investigación jurídica llevada a cabo por el autor por encargo del gobierno de Renania del Norte-Westfalia. En definitiva, no es solo que una actividad económica municipal en el sector energético sea lícita, sino que se fomenta que las empresas municipales se conviertan en competidores eficientes y capaces.

37 Vid. M. BuRGI, Neuer Ordnungsrahmen für die energiewirtschaftliche Betätigung der Kommunen, op. cit., p. 86.

38 Vid. R. Sieven, Kommunale Energieerzeugung in der Energiewende, op. cit., p. 15.

39 Para conocer las innovaciones legislativas en detalle, vid. M. BuRGI, Kommunalrecht, op. cit., $\$ 17$, ap. 38 . 


\subsection{Previsiones generales}

Todos los códigos municipales de los Länder contienen normas que condicionan si una actividad económica municipal puede ejercerse con base en la protección del municipio frente a los riesgos inherentes a esa actividad y de la situación presupuestaria municipal ${ }^{40}$. La estructura de la normativa de los Länder es fundamentalmente idéntica y contiene una triple limitación a la decisión de ejercer la iniciativa económica que no varía de una a otra salvo en cuestiones de detalle.

Según esta triple limitación, un primer requisito básico para el ejercicio municipal de actividades económicas es que sirva a un fin de interés público, como exigencia constitucional (vid. supra el apartado III.2). El municipio tiene un amplio margen para apreciar lo que considera fomento del interés público o del bienestar común ${ }^{41}$. Lo que no entra dentro de ese margen son las actividades que únicamente se dirijan a la obtención de lucro económico ${ }^{42}$. Específicamente en materia de energía dispone el apartado 1 del art. 107.a) GO NRW que la actividad municipal de suministro eléctrico, de gas y de calefacción se dirige siempre a la realización de un fin de interés público, algo que el legislador, por tanto, presume ${ }^{43}$.

Para evitar que el municipio se vea desbordado financiera u organizativamente, la actividad económica debe ser proporcionada (según su tipo y alcance) a la capacidad del municipio y dirigirse a cubrir la necesidad previsible que pueda existir en función del tamaño del municipio, su población y la estructura de la actividad que se va a realizar ${ }^{44}$. No obstante, salvo en casos extremos, no es esta una norma que vaya a suponer un gran obstáculo para la actividad municipal, ya que raras veces se darán las circunstancias para que se deba aplicar ${ }^{45}$.

Por último, la cláusula de subsidiariedad obliga a comprobar si habría que reconocer preferencia a la actividad económica privada sobre la pública. Según el art. 107.a).1.3 GO NRW, una actividad económica municipal solo es lícita si el fin público perseguido no puede ser cumplido "mejor y más eficientemente por otras empresas». En este punto la normativa de cada Land establece requisitos de distinta intensidad. Por ejemplo, el art. 87.1.4 del código municipal de Baviera exige que el fin no sea o pueda ser cumplido a través de terceros igual de bien y con la misma eficiencia. El municipio tendría entonces que cumplir ese fin público mejor y más eficientemente que los actores privados. Desde el punto de vista procedimental se exige a veces un estudio de mercado previo (así, el

\footnotetext{
${ }^{40}$ Cfr. M. BuRGI, Kommunalrecht, op. cit., $\$ 17$, ap. 37.

41 Vid. D. LÜCK, «Art. 87 GO», en J. DieTlein y J. Suerbaum (coords.), BeckOK Kommunalrecht Bayern, 8. a ed., C. H. Beck, Múnich, 2020, versión de 1 de noviembre de 2020, ap. 31.

42 Vid. M. Burgi, Kommunalrecht, op. cit., $\$ 17$, ap. 43.

43 Cfr. G. KASTER, «\$107a GO», en J. DieTlein y A. Heusch (coords.), BeckOK Kommunalrecht NRW, 14. ${ }^{a}$ ed., C. H. Beck, Múnich, 2020, versión de 1 de diciembre de 2020, ap. 9.

44 Vid. D. LÜCK, «Art. 87 GO», op. cit., ap. 37 y ss.

45 En este sentido, M. Burgi, Kommunalrecht, op. cit., $\$ 17$, ap. 45.
} 
art. 107 V GO NRW) ${ }^{46}$. El art. 107.a).1 GO NRW establece aquí una particularidad en el sector de la energía, al excepcionar la aplicación de la cláusula de subsidiariedad del art. 107.1.3 de la misma norma ${ }^{47}$. Por tanto, según el art. 107.a).1 GO NRW, la actividad municipal en el sector energético se somete al único requisito explícito de que su tipo y alcance sean proporcionados respecto de la capacidad financiera y organizativa del municipio ${ }^{48}$.

\subsection{Actividad suprarregional}

Como ya se ha dicho, la actividad económica suprarregional de los municipios no está protegida por el art. 28.2 GG (vid. supra el apartado III.2), por lo que la competencia municipal de asociarse con otros municipios no tiene en él su fundamento. No obstante, hay varios Länder que han previsto la posibilidad de que los municipios actúen económicamente también más allá de su territorio bajo ciertos requisitos. En este sentido, el art. 107.a) GO NRW encierra su verdadero significado en su apartado 3 al establecer que es admisible una actividad energética supralocal del municipio si concurren los requisitos ya mencionados (apartado III.3.3.1) para la actividad energética local y los intereses legítimos de las entidades locales afectadas no se vean menoscabados. Solo son intereses legítimos en este sentido aquellos que permitirían una restricción de la competencia en el mercado según la Ley del Sector Energético [art. 107.a).3.2 GO NRW]. Los mismos requisitos se aplican a la iniciativa económica municipal en el sector energético en mercados extranjeros [art. 107.a).3.3 GO NRW]. Para ello será necesario recabar la autorización del órgano de control de entidades locales (Kommunalaufsichtsbehörde) que corresponda [art. 107.a).3.4 GO NRW]. Se produce así una ampliación del ámbito de acción municipal conforme con el Derecho del Landy que, en principio, es compatible con las exigencias de la autonomía local como garantía institucional, con los derechos subjetivos a la autonomía de los demás municipios afectados y con los derechos fundamentales de los proveedores privados de energía ${ }^{49}$.

Esta norma es reflejo de las particularidades del mercado energético, que se caracteriza, sobre todo en el campo de la producción, por una estructura de oligopolio y por una dinamización de la actividad. La posibilidad de actuar en mercados supralocales y extranjeros permite así que los proveedores municipales de energía se conviertan en actores competitivos en el mercado energético. Y ello encuentra su fundamento en la necesidad imperativa de que la población reciba un suministro de energía fiable y a cambio de un precio razonable para que la comunidad pueda funcionar correctamente ${ }^{50}$. Así, la

\footnotetext{
46 Cfr. M. Burgi, Kommunalrecht, op. cit., $\$ 17$, ap. 46.

47 Cfr. G. KASTER, "\$107a GO», op. cit., ap. 11.

48 Vid. G. KASTER, «\$107a GO», op. cit., ap. 10.

49 En detalle M. BuRGI, Neuer Ordnungsrahmen für die energiewirtschaftliche Betätigung der Kommunen, op. cit., pp. 79 y ss.

50 Vid. G. Kaster, "\$107 GO», en J. Dietlein y A. Heusch (coords.), BeckOK Kommunalrecht NRW, 14. ${ }^{\text {a }}$ ed., C. H. Beck, Múnich, 2020, versión de 1 de diciembre de 2020, ap. 22.
} 
iniciativa municipal no solo es lícita, sino que incluso se fomenta a través de la adaptación del marco legal aplicable. Con ello se impulsa también la transición energética, en la medida en que empresas municipales de toda Alemania pueden operar instalaciones de producción de energía renovable de forma que aumente el porcentaje de energía renovable en el «mix» energético, lo que también beneficiará al clima (sobre las ventajas de una producción energética basada en energías renovables vid. supra el apartado I.2). Un motivo más para fomentar la iniciativa municipal en la producción energética es la esperable mayor aceptación de estas instalaciones asociada a mayores posibilidades de participación en ellas de la población a través de las empresas municipales (vid. supra el apartado II.1).

\section{CONCLUSIONES}

Las empresas municipales en Alemania juegan un papel cada vez más relevante en la producción de energía eléctrica como actores adicionales que garantizan el suministro energético de la población. El marco legal no solo permite esta situación, sino que la fomenta mediante la adaptación de la normativa de régimen local a las nuevas circunstancias, especialmente en el sector energético. Se trata con ello de establecer unos requisitos más livianos para las empresas municipales que desempeñen actividades económicas suprarregionales, de forma que estas empresas sean capaces de competir contra los proveedores privados en el mercado energético. Dada la capital importancia de esta actividad para el funcionamiento de la comunidad, estas empresas municipales deben contribuir al suministro energético de la población a cambio de un precio razonable, al desarrollo de energías renovables en el contexto de la transición energética (con los beneficios climáticos que conlleva) y a la aceptación de las decisiones en este ámbito involucrando a los ciudadanos en el proceso de planificación y toma de decisiones.

\section{BIBLIOGRAFÍA}

BURGI, M.: Neuer Ordnungsrahmen für die energiewirtschaftliche Betätigung der Kommunen, Boorberg, Múnich, 2010.

— «Daseinsvorsorge und Energieversorgung - Teilnahme der Kommunen am energiewirtschaftlichen Wettbewerb», en M. KMENT (coord.), Energiewirtschaft und kommunale Selbstverwaltung, Mohr Siebeck, Tübingen, 2018, pp. 1 y ss.

- Kommunalrecht, 6.a ed., C. H. Beck, Múnich, 2019.

Jung, Ch.: «Art. 106 AEUV», en Ch. CALLIES y M. RufFert (coords.), EUVIAEUV Kommentar, 5. a ed., C. H. Beck, Múnich, 2016.

KASter, G.: «\$107 GO», en J. DieTleIN y A. HeusCh (coords.), BeckOK Kommunalrecht NRW, 14. a ed., C. H. Beck, Múnich, 2020, versión de 1 de diciembre de 2020.

- «\$107a GO», en J. DieTLeIN y A. Heusch (coords.), BeckOK Kommunalrecht NRW, 14. a ed., C. H. Beck, Múnich, 2020, versión de 1 de diciembre de 2020. 
LÜCK, D.: «Art. 87 GO», en J. Dietlein y J. Suerbaum (coords.), BeckOK Kommunalrecht Ba-

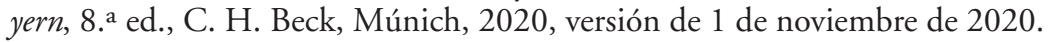

Pielow, J.-Ch., y SCHUELKen, T.: «Evolución de un mercado energético eficiente en Alemania», en M. Darnaculleta Gardella, J. Esteve Pardo y M. Ibler (coords.), Nuevos retos del Estado garante en el sector energético, Marcial Pons, Madrid, 2020, pp. 83 y ss.

SiEven, R.: Kommunale Energieerzeugung in der Energiewende, Universitätsverlag Göttingen, Göttingen, 2019. 
